I Universidade Estadual de Campinas, Departamento de Sociologia,

\title{
O SOCIAL, O POLÍTICO E A FORÇA DAS IDEIAS
}

André Botelho (20I9). O retorno da sociedade. Política e interpretações do Brasil. Petrópolis: Vozes.

$O$ retorno da sociedade. Política e interpretações do Brasil, de André Botelho, é uma obra interessada pela crítica do tempo presente e com ela comprometida. Como anuncia sua epígrafe, ${ }^{\mathrm{I}} \mathrm{me}$ nos do que render homenagens à "verdade do passado", está em questão construir a "inteligência de nosso tempo" por meio da comunicação entre as questões do presente e as interpretações do passado.

Uma leitura ressabiada certamente não deixará de indagar, afinal, quais seriam os motivos pelos quais tal comunicação se faria necessária. Organizados em três partes, os dez capítulos da obra - quatro deles em coautoria, com Antonio Brasil Jr., Andre Veiga Bittencourt, Elide Rugai Bastos e Lucas Carvalho - não se furtam da resposta, enfrentando-a à medida que um ex- tenso conjunto de temas e problemas é percorrido por meio de dois caminhos analíticos: o acúmulo teórico produzido pelo pensamento social na interpretação de alguns dos dilemas da sociedade brasileira; e a persistência do passado na modulação de aspectos da construção da cidadania e das bases sociais da democracia e das instituições no Brasil contemporâneo.

Caminhos que não correm em paralelo; ao contrário, vão se cruzando e se implicando ao longo da obra por meio daquele que se tem mostrado um dos mais persistentes e produtivos esforços teórico-metodológicos de seu autor: a reflexividade das conexões de sentido entre ideias, intelectuais e sociedade.

Comecemos, porém, pelo ponto inicial. Especialmente em sua primei- 
ra parte ("Baralhamento entre público e privado"), o acúmulo teórico produzido no interior do pensamento social brasileiro é reconstruído e mobilizado analiticamente pelo autor, o que se dá por meio da demonstração de que tal baralhamento ajudou a conformar modos recorrentes pelos quais debates públicos sobre a extensão dos direitos, o papel e a atuação do Estado e o alcance da ação coletiva foram construídos e ajudaram a moldar aspectos da luta social no país. Debates que ganharam, assim, progressiva expressão teórica e política em temas como corrupção e patrimonialismo, por exemplo.

Argumento decisivo para a economia do livro é apontar que tal baralhamento faz referência, a um só tempo, a problemas teóricos e a conflitos políticos, e nessa dupla condição gera um repertório-chave por meio do qual diferentes ideias foram produzidas, disputadas e colocadas em circulação. Para ler tal repertório, Botelho sintetiza e operacionaliza a categoria analítica "sequências", isto é, "um recurso analítico, da família do tipo ideal weberiano, forjado para repensar, na longa duração, diferentes interpretações sociológicas" (p. I4). Explorando obras de autores e autoras como Oliveira Vianna, Maria Sylvia de Carvalho Franco, Maria Isaura Pereira de Queiroz, Vitor Nunes Leal e Costa Pinto, os capítulos percorrem uma longa extensão de debates sobre as relações, mais ou menos conflitivas, entre Estado e sociedade, e apontam tanto para a característica cumulativa do conhecimento sociológico quanto para o mo- do como, para cada autor(a), as ideias são recolocadas tendo em vista os dilemas das variadas situações históricas, assumindo efeito variável em cada uma delas.

$\mathrm{Na}$ formulação do autor, a categoria "sequências" visa construir analiticamente "um espaço dinâmico de embates entre 'temporalidades', 'linguagens' e 'verdades' sobre as interpretações do Brasil” (p. 20). Um espaço marcado, assim, por uma "repetição com diferença”, posto que, como argumenta Botelho, novas ideias não emergem nem se realizam no vazio; antes incorporam, recusam ou dialogam com as interpretações que as precedem.

Se aqui está explicitada a característica da repetição, o lugar da diferença está, segundo o autor, na interação reflexiva entre ideias, intelectuais e sociedade. É, portanto, na "repetição com diferença" de uma "sequência" que texto e contexto se implicam. Esse movimento analítico ganha corpo por meio da demonstração de como questões colocadas pela sociedade se repõem e se renovam ao longo do processo histórico.

Como uma obra é composta, também, por seus agradecimentos, as páginas em branco que Botelho preenche ao longo de $O$ retorno da sociedade carregam as cores e as texturas de seus diálogos intelectuais, que se expressam em formulações como, por exemplo, a "repetição com diferença", que persegue a provocação de Silviano Santiago (20I9) de que a repetição sempre produziria a diferença. Ao mobilizá-la em seu argumento, o autor 
demonstra o caráter reiterativo e a dimensão contingente sem os quais as interações entre ideias, intelectuais e sociedade não poderiam ser tomadas reflexivamente.

Se o caráter reiterativo dessa interação já estava presente na reflexão de Botelho desde os debates com as sugestões teórico-metodológicas de Gildo Marçal Brandão (2007), a ênfase na contingência e, especialmente, na reflexividade, que estrutura a obra, é bastante devedora do diálogo com Santiago. E guarda, ainda, profundo diálogo com as formulações teórico-metodológicas de Elide Rugai Bastos (2002) acerca dos efeitos sociais das ideias, indicando que tanto elas quanto os intelectuais são partes constitutivas do confronto político e das lutas pela cultura. ${ }^{2}$

Chegamos aqui ao segundo caminho analítico da obra: a comunicação entre questões do passado e interpretações do presente. Tal comunicação é certamente aquilo que permite flagrar a aludida "repetição com diferença". Exemplares, nesse sentido, são os capítulos que compõem a segunda parte do livro ("A política na sociedade: fios contemporâneos"). Nela, Botelho retoma a reflexividade entre ideias, intelectuais e sociedade para demonstrar que os diferentes modos de ler e interpretar o país estiveram e permanecem - sujeitos à constante atualização de leituras críticas que recusam ou retomam suas proposições, numa evidência de que as "interpretações do Brasil" integram o horizonte imaginativo da elaboração de categorias, conceitos e métodos que marcam a prática profissional da sociologia realizada no país.

Longe de argumentar sobre uma eventual especificidade nacional, o autor indica que o pensamento social constitui um corpo de problemas e de soluções intelectuais que ajudaram a dar densidade ao processo de sistematização teórica e de organização metodológica da sociologia. Afinal, ao relacionar, reflexivamente, categorias e conceitos para análise da interação entre sociedade e política, o pensamento social oferece, ainda, um repertório para "o enfrentamento de velhas e novas questões postas pelo pelo desenvolvimento social" (p. 56).

$O$ retorno da sociedade evidencia, então, que um contexto possui muitos tempos e que as várias camadas de um texto não só guardam as inflexões de tais tempos, como também são marcadas pelo chão intelectual no qual se realizam. Ou seja, o acúmulo de conhecimento não é mero inventário de autores e ideias, assim como a produção da diferença - interpretativa e histórica - só se pode realizar na imbricação entre textos e contextos.

Articulando os dois caminhos analíticos que estruturam a obra, Botelho desenvolve a terceira e última parte ("Interpretar interpretações do Brasil"), dedicada a explorar e a propor uma agenda para o pensamento social como área de pesquisa e campo temático. É no interior dessa agenda que o retorno da sociedade que dá título à obra ganha densidade teórica e metodológica, apontando para duas dimensões fundamentais: de um lado, a necessidade de voltar a atenção para a persis- 
tência de um passado que não passa, isto é, "de valores e práticas autoritárias de socialização e de orientação das condutas, de afirmação das hierarquias nas mais diferentes relações sociais e de reiteração das desigualdades" (p. I I); de outro, a discussão sobre o alcance da ação coletiva no país, num debate que recorta a interação "ação" e "estrutura" como problema de pesquisa e aponta que "nem a ação coletiva deveria ser vista em termos voluntaristas, nem tampouco as estruturas políticas como estáticas" (p. I 2).

Como já indicado, ao longo de suas três partes, O retorno da sociedade sustenta que nem as ideias e nem as instituições se realizam num vazio de relações sociais, o que marca, decisivamente, a natureza da política e de sua interação com a sociedade. Perseguindo as bases sociais das instituições, Botelho ressalta a importância de uma leitura sociológica da política, isto é, uma análise que tome a interação entre Estado e sociedade como relação, situando assim sua historicidade, mas também possibilitando que tal relação seja lida em termos de generalidade (p. I27-I 29).

Normativamente, $\mathrm{O}$ retorno da sociedade aponta para a concretude da base social na qual ideias e instituições se realizam; uma concretude que, no entanto, não significa determinação, mas sim interação reflexiva entre o social e o político. Aprofundando o argumento do autor, temos que as ideias estão nos textos, mas também nos modos de dizer e naquilo que é dizível.

A tarefa crítica do tempo presente, portanto, não pode ficar escondida no antiquário das genealogias sobre o passado, mas também deve evitar as armadilhas de se "refugiar no tempo presente" (p. 20). O caminho trilhado pelo autor para fugir ao impasse é estabelecer a comunicação entre passado e presente por meio da articulação entre teoria sociológica e pensamento social, perseguindo aquilo que adequadamente nomeia como uma "sociologia historicamente orientada” (p.20).

Como demonstrado em $O$ retorno da sociedade, o engajamento na reflexão sobre o movimento reflexivo entre as ideias e a empiria do mundo social permite a investigação das bases sociais das instituições, das visões de mundo, das ideologias e fabulações implicadas na realização de projetos conservadores, liberais ou progressistas. Se a sociedade retorna, a obra de Botelho não deixa de mostrar que as ideias concorrem, reflexivamente, para produzir a diferença que permite reagir contra e, sobretudo, refazer a imaginação sociológica.

Recebido em 28/2/2020 | Aprovado em Io/3/2020 


\section{NOTAS}

I Retirada do livro Critique et vérité (1966) de Roland Barthes: "assim, pode-se travar, no seio da obra crítica, o diálogo de duas histórias, a do autor e a do crítico. Mas esse diálogo é egoisticamente todo desviado para o presente: a crítica não é uma homenagem à verdade do passado ou à verdade do 'outro', ela é a construção da inteligência de nosso tempo".

2 No caso de O retorno da sociedade, a parceria e o diálogo com a autora estão expressos, também, na coautoria do capítulo 9 ("Por uma sociologia dos intelectuais").

\section{REFERÊNCIAS BIBLIOGRÁFICAS}

Bastos, Elide Rugai. (2002). Pensamento social da escola sociológica paulista. In: Miceli, Sergio. O que ler na ciência social brasileira, I970-2002. São Paulo/Brasília: Anpocs/Editora Sumaré/Capes.

Brandão, Gildo Marçal. (2007). Linhagens do pensamento político brasileiro. São Paulo: Hucitec.

Santiago, Silviano. (2019) [1978]. Uma literatura nos trópicos. Recife: Cepe.

Mariana Miggiolaro Chaguri é doutora em sociologia e professora do Departamento de Sociologia e do Programa de Pós-Graduação em Sociologia da Universidade Estadual de Campinas. Atua especialmente nos temas ligados ao pensamento social e estudos pós-coloniais. Entre suas publicações recentes estão os artigos "Essayism and sociology in Brazil: notes on colonization, slavery and nation", em The American Sociologist (2019), e "Women's war: gender activism in the Vietnam war, and in the wars for the Kurdish autonomy", em coautoria com Flávia X. M. Paniz, em Sociologia \& Antropologia (2019). 